\title{
Direct CO Oxidation by Lattice Oxygen on Zr-Doped Ceria Surfaces
}

\author{
Zongxian Yang $\cdot$ Zhaoming Fu $\cdot$ Yanning Zhang $\cdot$ \\ Ruqian Wu
}

Received: 2 March 2010/Accepted: 31 August 2010/Published online: 21 September 2010

(C) The Author(s) 2010. This article is published with open access at Springerlink.com

\begin{abstract}
Systematic density-functional calculations have been performed to address an important issue for $\mathrm{CO}$ oxidation on redox ceria: the role of lattice oxygen. One major findings is that $\mathrm{CO}$ easily grasps one lattice oxygen atom to form $\mathrm{CO}_{2}^{-}$and $\mathrm{CO}_{2}$ on $\mathrm{CeO}_{2}$ (111) and $\mathrm{Ce}_{0.75} \mathrm{Zr}_{0.25} \mathrm{O}_{2}$ (111) with small activation energies. $\mathrm{Zr}$ dopants facilitate the reduction of $\mathrm{Ce}^{+4}$ to $\mathrm{Ce}^{+3}$ and hence weaken the $\mathrm{Ce}-\mathrm{O}$ bonds, which benefit the direct formation and release of $\mathrm{CO}_{2}$.
\end{abstract}

Keywords Density-functional theory (DFT) $\cdot$ CO oxidation $\cdot$ Zr-doped ceria $\cdot$ Vienna ab-initio simulation package (VASP)

\section{Introduction}

Rational design of robust nanocatalysts for $\mathrm{CO}$ oxidation and $\mathrm{NO}_{\mathrm{x}}$ reduction is crucial for many important applications such as pollution control and energy production. Owing to its particular redox properties, ceria has been extensively utilized in catalytic converters $[1,2]$.

\footnotetext{
Z. Yang (ه)

College of Physics and Information Engineering,

Henan Normal University, Xinxiang, Henan, 453007,

People's Republic of China

e-mail: yzx@henannu.edu.cn

Z. Fu

Department of Physics, Fudan University, Shanghai 200433,

People's Republic of China

Y. Zhang · R. Wu ( $)$

Department of Physics and Astronomy, University of California, Irvine, CA 92697-4575, USA

e-mail: wur@uci.edu
}

Significantly, its redox performance can be further enhanced by the presence of various dopants, such as $\mathrm{Zr}^{4+}$, $\mathrm{Ca}^{2+}$ and some noble metal [3-6]. This offers a great opportunity to control the activity and selectivity of oxide catalysts with the aid of innovative nanofabrication techniques. One of the most important tasks for fundamental research is to attain a clear understanding of mechanisms: (1) how lattice oxygen atoms contribute toward chemical reactions and, (2) how dopants modify surface activity. It is widely believed that $\mathrm{CO}$ directly combines with lattice oxygen atom on ceria, through the Mars-van Krevelen mechanism [7]. However, the relevant reaction dynamics has not been satisfactorily unravelled. Shapovalov and Metiu [8] recently investigated the effects of noble metal dopants $(\mathrm{Au}, \mathrm{Ag}$ and $\mathrm{Cu}$ ) on the energetics of $\mathrm{CO}$ oxidation on $\mathrm{CeO}_{2}$ (111). Their density functional calculations indicate that bonds between lattice oxygen and metal atoms in oxide are significantly weakened by the presence of dopants and hence the doped $\mathrm{CeO}_{2}$ (111) surfaces become much more active in both releasing $\mathrm{CO}_{2}$ and healing vacancies. Chen et al. [9] also found that $\mathrm{Au}$ adsorption on Ce-vacancies activates $\mathrm{O}$ atoms nearby. In particular, releasing and restocking oxygen through the redox processes on ceria involve the $\mathrm{Ce}^{4+} / \mathrm{Ce}^{3+}$ transformation and therefore it is crucial to study the effect of irreducible dopants (e.g., $\mathrm{Zr}^{4+}$ and $\mathrm{Ca}^{2+}$ dopants) on the charge state of Ce.

The present paper reports results of systematic density functional studies on the formation of $\mathrm{CO}_{2}$ through direct combination of $\mathrm{CO}$ and lattice oxygen on the clean and doped ceria. Interestingly, we found a bent $\mathrm{CO}_{2}$,ad structure as the transition state for the reaction: $\mathrm{CO}+$ oxide $\rightarrow$ $\mathrm{CO}_{2, \text { gas }}+$ deficient oxide, on the clean ceria (111) surface. $\mathrm{Zr}$-dopants further weaken the $\mathrm{Ce}-\mathrm{O}$ bonds in the substrate and therefore facilitate direct formation of $\mathrm{CO}+\mathrm{O}_{\mathrm{L}} \rightarrow$ 
$\mathrm{CO}_{2}$,gas. These findings provide clear evidence of lattice oxygen contribution toward $\mathrm{CO}$ oxidation on ceria, imperative for understanding of catalytic properties of oxides.

\section{Methodology and Computational Details}

We used the Vienna ab-initio simulation package (VASP) [10] to solve the spin-polarized Kohn-Sham equations. The exchange and correlation interaction among electrons were described at the level of the generalized gradient approximation (GGA), using the Perdew-Burke-Ernzerhof (PBE) formula [11]. The Ce-5s5p5d4f6s, O-2s $2 p, \mathrm{C}-2 s 2 p$, and $\mathrm{Zr}-4 s 4 p 5 s 4 d$ were treated as valence electrons while the ionic cores were represented by the projector augmented wave (PAW) potentials $[12,13]$. To appropriately describe the on-site Coulomb repulsion among Ce $4 \mathrm{f}$ electrons, we introduced a Hubbard parameter, $U$, according to the GGA + U scheme [14-17]. The value of $U$ was chosen to be $5 \mathrm{eV}$, for the best fitting against experimental results of the bulk $\mathrm{CeO}_{2}$ and $\mathrm{CeO}_{2}-x[15,16]$. An energy cutoff of $400 \mathrm{eV}$ was used for the plane wave expansion. The Monkhorst-Pack method [18], e.g., with $(4 \times 4 \times 4)$ grids for the bulk $\mathrm{CeO}_{2}$, was adopted for the Brillouin zone sampling. The lattice size and atomic positions were optimized with a criterion that requires force on each atom to be less than $0.02 \mathrm{eV} / \mathrm{A}$. The climbing image nudged elastic band method (CI-NEB) [19] was employed to investigate the transition states and minimum energy paths (MEP) for adsorption and oxidation of $\mathrm{CO}$ on $\mathrm{CeO}_{2}$ (111).

The calculated lattice constant for the bulk $\mathrm{CeO}_{2}$ is 5.48 $\AA$, a value that agrees well with the experimental data, 5.41 $\AA$ [20]. The bulk $\mathrm{Ce}_{0.75} \mathrm{Zr}_{0.25} \mathrm{O}_{2}$ was constructed by substituting one $\mathrm{Ce}$ in the 12-atom cubic cell of ceria with $\mathrm{Zr}$, and its optimized lattice size is $5.42 \AA$, also in good accordance with previous theoretical value, $5.39 \AA$ [21]. For the free $\mathrm{CO}$ and $\mathrm{CO}_{2}$ molecules, it is known that GGA leads to somewhat overestimated bond lengths but appropriate formation energies. Here, the calculated formation energies of $\mathrm{CO}$ and $\mathrm{CO}_{2}$ molecules are 258.9 and $202.5 \mathrm{kcal} / \mathrm{mol}$, respectively, in good agreement with the experimental values of 259 and $191.2 \mathrm{kcal} / \mathrm{mol}$. (c.f. [22] and references therein) Apparently, the computational approach and parameters are adequate for the description of both reactants and substrates.

We chose the (111) and (110) surfaces of clean and $\mathrm{Zr}$-doped ceria to demonstrate the orientation dependence. They are two stable low index surfaces and have been extensively studied $[23,24]$. It is known that $\mathrm{CO}$ takes the Ce site on the clean $\mathrm{CeO}_{2}$ (111) surface but the adsorption energy is very small, $3.9 \mathrm{kcal} / \mathrm{mol}$ [25] from GGA calculations and $4.2 \mathrm{kcal} / \mathrm{mol}$ from the present $\mathrm{GGA}+\mathrm{U}$ calculations. Therefore, $\mathrm{CO}$ molecules are highly mobile on this substrate under ambient condition. In contrast, $\mathrm{CO}$ tends to strongly bind to $\mathrm{CeO}_{2}(110)$ at the O-bridge site $[25,26]$. Studies of these two surfaces thus cover extremes of ceria toward catalyzing $\mathrm{CO}$ oxidation.

The $\mathrm{CeO}_{2}$ (111) and $\mathrm{Ce}_{0.75} \mathrm{Zr}_{0.25} \mathrm{O}_{2}$ (111) surfaces were modeled with periodic slabs consisting of 12 layers of $\mathrm{Ce}(\mathrm{Zr})$ and $\mathrm{O}$ atoms and a vacuum region of $13 \AA$ thick in the between. Atoms in the bottom six layers were fixed at their bulk-like positions whereas those in the top six layers were fully relaxed. The $\mathrm{CeO}_{2}$ (110) and $\mathrm{Ce}_{0.75} \mathrm{Zr}_{0.25} \mathrm{O}_{2}$ (110) surfaces were modeled with slabs of 6 layers of $\mathrm{Ce}(\mathrm{Zr})$ and $\mathrm{O}$ atoms and a vacuum region of $13 \AA$ thick. The two bottommost layers were fixed in the structural optimization procedure. Large unit cells in the lateral plane were used to mimic cases with small $\mathrm{CO}$ coverage.

\section{Results and Discussion}

It is known that $\mathrm{CO}$ weakly interacts with the clean $\mathrm{CeO}_{2}$ (111) surface, with an adsorption energy of $3.9 \mathrm{kcal} / \mathrm{mol}$ and the preferential adsorption site is on top of Ce. However, this ground state adsorption geometry might not be directly relevant to the redox process of $\mathrm{CO}$ on oxides depicted as: $\mathrm{CO}+\mathrm{O}_{\mathrm{L}} \rightarrow \mathrm{CO}_{2}$, gas $+\mathrm{d}_{\mathrm{L}}$. Here, $\mathrm{O}_{\mathrm{L}}$ and $\mathrm{d}_{\mathrm{L}}$ represent lattice oxygen atom and lattice deficiency left on the substrate after the reaction, respectively. Obviously, one crucial step is the onset of the formation of $\mathrm{O}-\mathrm{C}-\mathrm{O}_{\mathrm{L}}$ bonds. To explore this possibility, we investigated various metastable adsorption geometries for $\mathrm{CO}$ on $\mathrm{CeO}_{2}$ (111). As a result, we found an important configuration shown in Fig. 1a that has a bent $\mathrm{CO}_{2}$,ad structure, formed with $\mathrm{CO}$ and a lattice $\mathrm{O}$ atom. Here, the two $\mathrm{C}-\mathrm{O}$ bonds are $1.24 \AA$ and $1.37 \AA$ long and the $\mathrm{O}-\mathrm{C}-\mathrm{O}$ bond angle is $125.5^{\circ}$, indicating strong binding between $\mathrm{CO}-\mathrm{O}_{\mathrm{L}}$. Through the Bader charge analysis [27], we found that the total number of valence electrons in the bent $\mathrm{CO}_{2}$,ad group is 17.2, which is one electron more than that of a free $\mathrm{CO}_{2}$ molecule. We hence call this charged bent $\mathrm{CO}_{2}$,ad structure $\mathrm{CO}_{2}^{-}$species below. Using the ground state adsorption configuration, the bent $\mathrm{CO}_{2}$,ad group and $\mathrm{CO}_{2}$, gas $+\mathrm{d}_{\mathrm{L}}$ as initial-final geometries, the reaction path and adsorption energy were obtained through the CI-NEB approach. In Fig. 2, it is interesting to find out that the formation of the $\mathrm{CO}_{2}^{-}$species is actually very close to the transition state. The activation energy, which directly determines the reaction rate, is about $14.6 \mathrm{kcal} / \mathrm{mol}$. Therefore, this reaction has a high probability to occur under typical reaction conditions. Furthermore, total energy calculations indicate that the 
reaction pathway $\mathrm{CO}_{\text {gas }} \rightarrow \mathrm{CO}_{\text {ad }} \rightarrow \mathrm{CO}_{2} / \mathrm{CeO}_{2}(111) \rightarrow$ $\mathrm{CO}_{2}$, gas $+\mathrm{d}_{\mathrm{L}}$ is exothermic, with an energy gain of $9.5 \mathrm{kcal} / \mathrm{mol}$. Clearly, the $\mathrm{CO}_{2}^{-}$species prefers to desorb as a group from the $\mathrm{CeO}_{2}$ (111) substrate for the completion of $\mathrm{CO}$ oxidation, after overcoming a very small energy barrier $(\sim 1.0 \mathrm{kcal} / \mathrm{mol})$. One may perceive a reaction dynamics that $\mathrm{CO}$ pulls out one lattice $\mathrm{O}$ from the $\mathrm{CeO}_{2}$ (111) surface and directly oxidize in gas phase. Shapovalov and Metiu [8] also found the bent $\mathrm{CO}_{2}$ structure for $\mathrm{CO}$ on $\mathrm{CeO}_{2}(111)$ but they didn't mention the charge state. The presence of charge in $\mathrm{CO}_{2}^{-}$is essential for its bent shape since it should behave like a $\mathrm{NO}_{2}$ molecule which has an $\mathrm{O}-\mathrm{N}-\mathrm{O}$ bond-angle of $\left(132^{\circ} \pm 3^{\circ}\right)$ [28]. If we add an electron to a free $\mathrm{CO}_{2}$ molecule, the $\mathrm{O}-\mathrm{C}-\mathrm{O}$ bond-angle also changes from $180^{\circ}$ to $151^{\circ}$. The curves of density of states (DOS) of ideal, bent and adsorbed $\mathrm{CO}_{2}$ molecule are shown in Fig. 3. Unlike a neutral $\mathrm{CO}_{2}$ molecule, the bent $\mathrm{CO}_{2}$ structure has a much smaller gap between the $5 \sigma \rightarrow 2 \pi^{*}$ states. The energy difference between the HOMO and LUMO states changes from $\sim 6.5 \mathrm{eV}$ for a neutral $\mathrm{CO}_{2}$ molecule to $\sim 2.5 \mathrm{eV}$ for a bent $\mathrm{CO}_{2}$ structure. This makes it much easier to host additional electrons in the $2 \pi^{*}$ state, such as in $\mathrm{CO}_{2}^{-}$. On $\mathrm{CeO}_{2}(111)$, the $2 \pi^{*}$ state further splits to two peaks $\sim 1.0 \mathrm{eV}$ apart, because of the effect of the substrate. On the other side, the formation of $\mathrm{CO}-\mathrm{O}_{\mathrm{L}} \rightarrow \mathrm{CO}_{2}^{-}$also donates one electron back to oxide. Note that the single state charge density also displays contributions around the $\mathrm{Ce}$ atoms in Fig. 1a. This triggers complete $\mathrm{Ce}^{4+} \rightarrow \mathrm{Ce}^{3+}$ transformation for one Ce atom if the local symmetry is broken, and will reduce the barrier of the desorption of $\mathrm{CO}_{2}^{-}$and neutral $\mathrm{CO}_{2}$ for the completion of $\mathrm{CO}$ oxidation.

More dramatic effect is found when $\mathrm{Zr}$ dopant is introduced. $\mathrm{Zr}$ is irreducible and thus may substantially change the local chemistry. On the $\mathrm{Ce}_{0.75} \mathrm{Zr}_{0.25} \mathrm{O}_{2}$ (111) surface, neutral $\mathrm{CO}_{2}$ molecule can be directly (non-activated) formed when $\mathrm{CO}$ is adsorbed on top the surface $\mathrm{O}$ atoms that are adjacent to the $\mathrm{Zr}$ dopant. As shown in Figs. $1 \mathrm{~b}$ and $4 \mathrm{a}$, a straight $\mathrm{O}-\mathrm{C}-\mathrm{O}$ geometry is the most stable adsorption configuration for $\mathrm{CO}$ on the $\mathrm{Ce}_{0.75} \mathrm{Zr}_{0.25} \mathrm{O}_{2}$ (111) surface, with an adsorption energy of $18.5 \mathrm{kcal} / \mathrm{mol}$. The $\mathrm{C}-\mathrm{O}$ bond length and the $\mathrm{O}-\mathrm{C}-\mathrm{O}$ angle are $1.20 \AA$ and $179.7^{\circ}$, already very close to those of a free $\mathrm{CO}_{2}$ molecule, $1.20 \AA$, and $180^{\circ}$, respectively. The Bader analysis [27] shows that the $\mathrm{CO}_{2}$ species has 16.01 valence electrons, and thus is neutral. The first reaction step for $\mathrm{CO}$ oxidation on $\mathrm{Ce}_{0.75} \mathrm{Zr}_{0.25} \mathrm{O}_{2}$ (111) can be depicted as: $\mathrm{CO}_{\mathrm{ad}}+\mathrm{O}_{\mathrm{L}} \rightarrow$ $\mathrm{CO}_{2 \text {,ad }} \rightarrow \mathrm{CO}_{2, \text { gas }}+\mathrm{d}_{\mathrm{L}}$. The energetics for the three reaction steps are given in Fig. $4 \mathrm{a}$, where it is obvious that $\mathrm{CO}$ oxidation may take place easily since $\mathrm{CO}_{\mathrm{ad}}+\mathrm{O}_{\mathrm{L}} \rightarrow$ $\mathrm{CO}_{2}$,ad has zero energy barrier and $\mathrm{CO}_{2}$,ad $\rightarrow \mathrm{CO}_{2}$, gas $+\mathrm{d}_{\mathrm{L}}$ only requires a small desorption energy, $6.5 \mathrm{kcal} / \mathrm{mol}$.
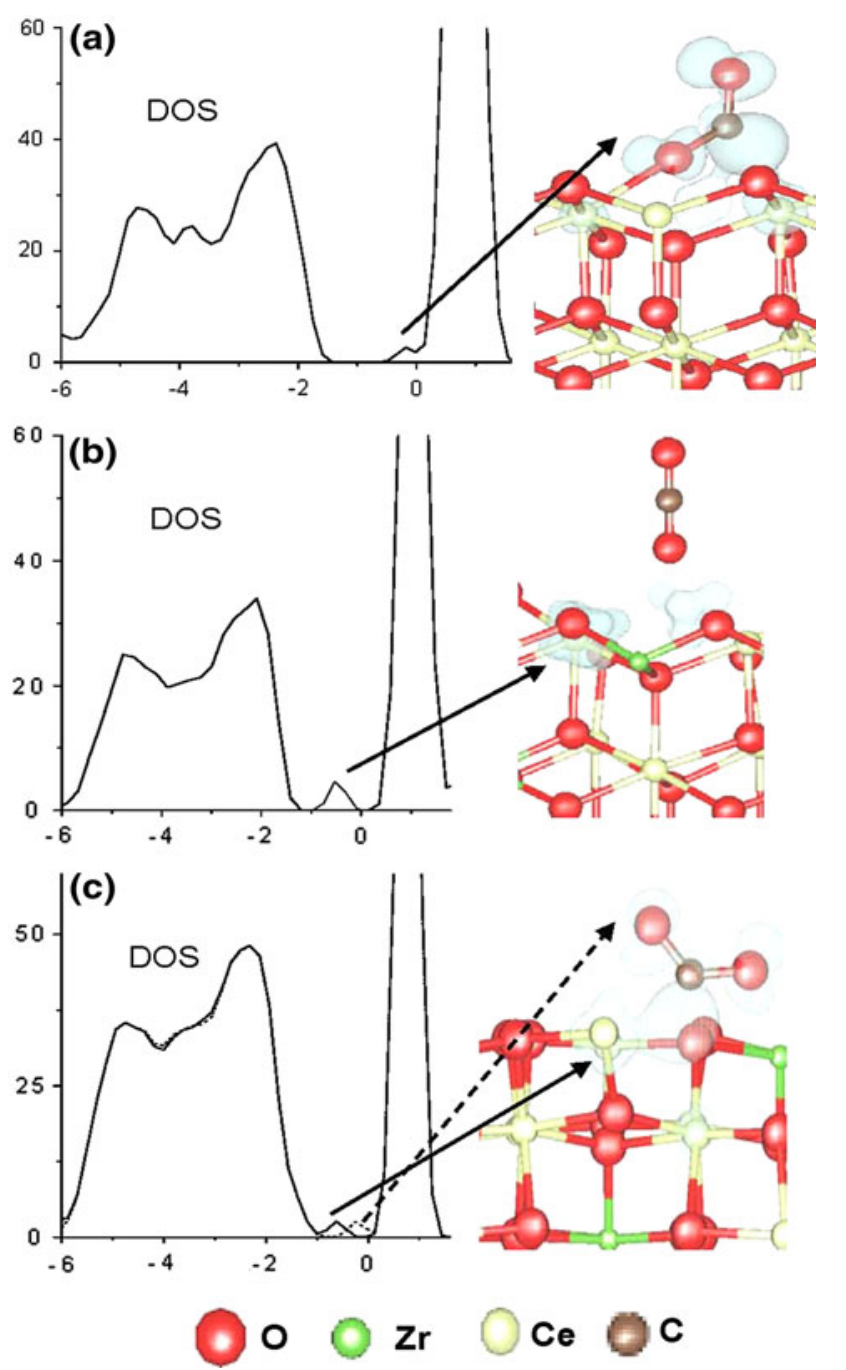

Fig. 1 Optimized structures with the density of states near the Fermi level and the distribution of the excess electrons for $\mathrm{CO}$ adsorbed on a $\mathrm{CeO}_{2}(111)$, b $\mathrm{Ce}_{0.75} \mathrm{Zr}_{0.25} \mathrm{O}_{2}(111)$, and $\mathbf{c} \mathrm{Ce}_{0.75} \mathrm{Zr}_{0.25} \mathrm{O}_{2}$ (110). All the calculations were done with spin polarization. In Fig. 1a and b, only the majority spin states are shown since the systems converged to nonmagnetic states. In panel c, the solid and dashed curves represent results in the majority and minority spin channels, respectively. Here and in the following figures, yellow, red, green and brown spheres represent the $\mathrm{Ce}, \mathrm{O}, \mathrm{Zr}$, and $\mathrm{C}$ atoms, respectively

Apparently, $\mathrm{Zr}$ dopants strongly change the reaction mechanism of $\mathrm{CO}$ oxidation on the ceria (111) surface. Unlike the clean $\mathrm{CeO}_{2}$ (111) surface, $\mathrm{Ce}_{0.75} \mathrm{Zr}_{0.25} \mathrm{O}_{2}$ (111) efficiently attract $\mathrm{CO}$ molecules from the gas phase, as suggested by the sizable adsorption energy of $18.5 \mathrm{kcal} /$ mol. On the other hand, $\mathrm{Zr}$ dopants reduce the energy cost for the formation of oxygen vacancy [4, 29] and thus increase the mobility of lattice oxygen atoms nearby [30]. If we define the formation energy of an $\mathrm{O}$ vacancy as: $\mathrm{E}_{\mathrm{vac}}=\mathrm{E}\left(\right.$ cell $\left._{\mathrm{vac}}\right)+1 / 2 \mathrm{E}\left(\mathrm{O}_{2}\right)-\mathrm{E}($ cell $)$, where the $\mathrm{E}$ $\left(\right.$ cell $\left._{\mathrm{vac}}\right)$ and $\mathrm{E}$ (cell) are total energies of the optimized surfaces with and without an oxygen vacancy, and $\mathrm{E}\left(\mathrm{O}_{2}\right)$ is 


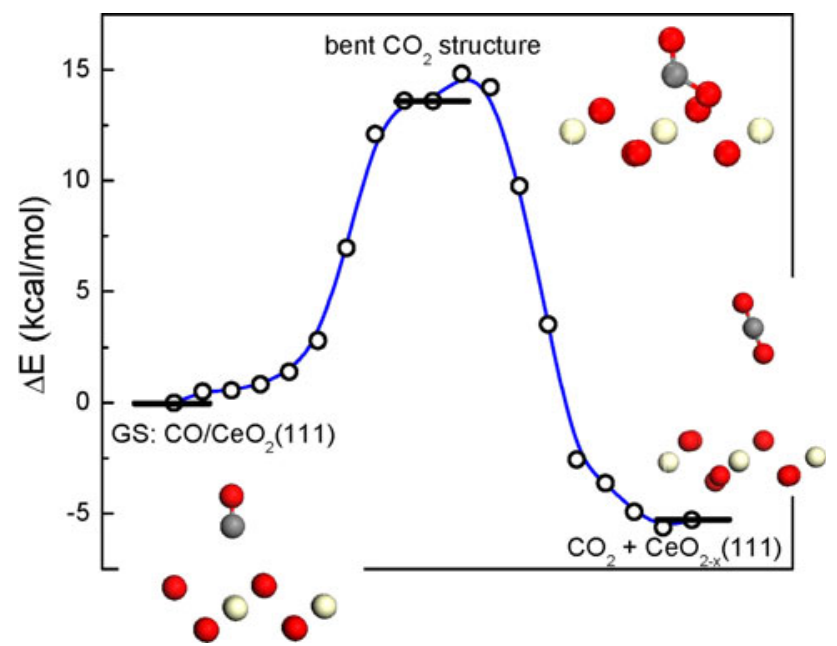

Fig. 2 The calculated energy change along the optimized reaction path for $\mathrm{CO}$ oxidation on $\mathrm{CeO}_{2}$ (111) obtained through the NEB approach. Insets also show the atomic structures of $\mathrm{CO}$ adsorption state, transition state and the final state. Red balls are for oxygen, grey balls are for carbon and white balls are for Ce, respectively

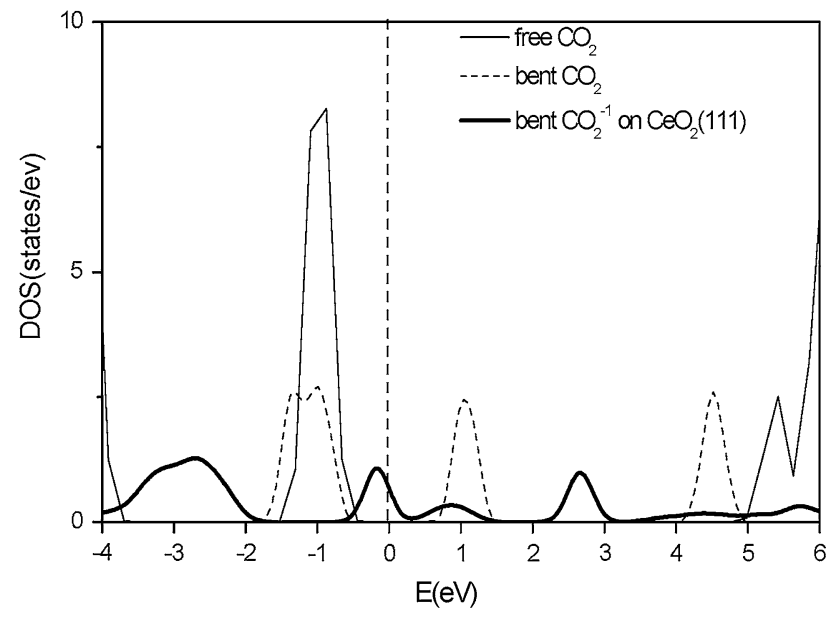

Fig. 3 The density of states (DOS) for a $\mathrm{CO}_{2}$ molecule in gas phase (thin solid line), a bent $\mathrm{CO}_{2}$ molecule (thin dashed line), and a bent $\mathrm{CO}_{2 \text {,ad }}^{-1}$ species on the $\mathrm{CeO}_{2}$ (111) surface (thick solid line)

the total energy of an oxygen molecule in the gas phase, the calculated value of $\mathrm{E}_{\mathrm{vac}}$ for the undoped $\mathrm{CeO}_{2}$ (111) surface is $2.87 \mathrm{eV}$ per vacancy. By contrast, $\mathrm{E}_{\mathrm{vac}}$ of the $\mathrm{Ce}_{0.75} \mathrm{Zr}_{0.25} \mathrm{O}_{2}$ (111) surface is reduced by approximately $20 \%$ to $2.35 \mathrm{eV}$. From the DOS curve plotted in Fig. 1b, the gap state localizes on two of the Ce cations around the vacancy, indicating that the two surface $\mathrm{Ce}^{4+}$ cations are already reduced to $\mathrm{Ce}^{3+}$ cations. The surface structure is therefore somewhat distorted. In Fig. 1b, the surface $\mathrm{Ce}-\mathrm{O}$ distances near the adsorption site elongated by $0.06 \AA$ as compared to those before $\mathrm{Zr}$-doping. Since the size of $\mathrm{Ce}^{3+}$ is larger than that of $\mathrm{Ce}^{4+}$, the $\mathrm{CO}_{2 \text {,ad }}$ group is somewhat "pushed" outward for the accommodation of $\mathrm{Ce}^{3+}$. Meanwhile, $\mathrm{Zr}^{4+}$ is smaller than $\mathrm{Ce}^{4+}$, and hence provides (a)
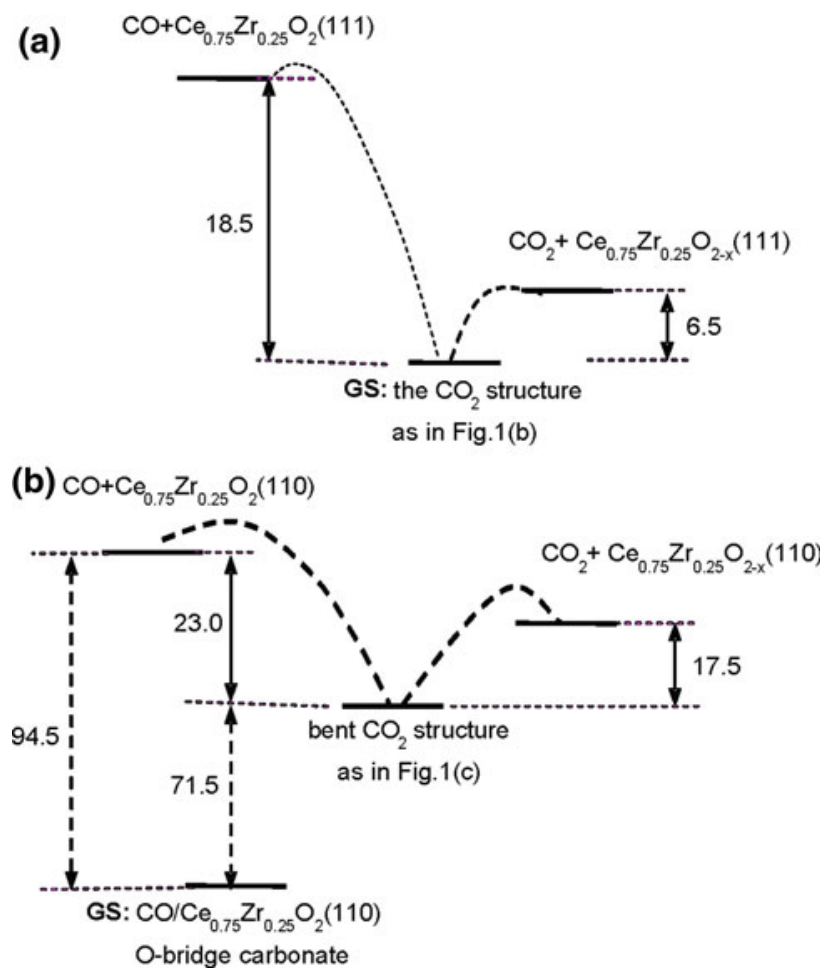

Fig. 4 Sketches of energy diagrams for $\mathrm{CO}$ adsorption and oxidation on a $\mathrm{Ce}_{0.75} \mathrm{Zr}_{0.25} \mathrm{O}_{2}(111)$ and $\mathbf{b} \mathrm{Ce}_{0.75} \mathrm{Zr}_{0.25} \mathrm{O}_{2}$ (110). "GS" denotes the ground state for each system. " $\mathrm{CO}+\mathrm{Ce}_{0.75} \mathrm{Zr}_{0.25} \mathrm{O}_{2}$ (111)" and " $\mathrm{CO}+\mathrm{Ce}_{0.75} \mathrm{Zr}_{0.25} \mathrm{O}_{2}$ (110)" refer to the states of free $\mathrm{CO}$ molecules with clean unreduced substrates before adsorption, while " $\mathrm{CO}_{2}+$ $\mathrm{Ce}_{0.75} \mathrm{Zr}_{0.25} \mathrm{O}_{2}-\mathrm{x}(111)$ " and " $\mathrm{CO}_{2, \text { gas }}+\mathrm{Ce}_{0.75} \mathrm{Zr}_{0.25} \mathrm{O}_{2}-\mathrm{x}(110)$ " represent the states of free $\mathrm{CO}_{2}$ molecules with reduced substrates after $\mathrm{CO}_{2}$ desorption

more space and releases the stress for the creation of $\mathrm{Ce}^{3+}$ cations. Note: The radius of $\mathrm{Zr}^{4+}(0.84 \AA)$ is smaller than those of $\mathrm{Ce}^{4+}(0.97 \AA)$ and $\mathrm{Ce}^{3+}(1.19 \AA)$.

It was believed that $\mathrm{CeO}_{2}(110)$ surface is possibly more active than the $\mathrm{CeO}_{2}$ (111) surface. In recent calculations $[15,31]$, it was found that O-vacancy may form more easily on the (110) surface than (111) surface of ceria and the departure of a neutral $\mathrm{O}$ atom leads to $\mathrm{Ce}^{4+} \rightarrow \mathrm{Ce}^{3+}$ transformation of two $\mathrm{Ce}$ atoms on $\mathrm{CeO}_{2}$ (110) [15]. However, no metastable $\mathrm{CO}_{2}$ configuration was found for $\mathrm{CO}$ on $\mathrm{CeO}_{2}(110)$ and $\mathrm{CO}$ takes strong adsorption at the $\mathrm{O}$ bridge site as reported before. Therefore, the conjecture that correlates the formation energy of $d_{L}$ to the activity of oxides is questionable. The presence of $\mathrm{Zr}$ dopant promotes the $\mathrm{Ce}^{4+} \rightarrow \mathrm{Ce}^{3+}$ reduction and hence should assist the release of $\mathrm{O}_{\mathrm{L}}$, as attested by the reduction of the formation energy of oxygen vacancy. The calculated $\mathrm{E}_{\mathrm{vac}}$ values are 2.30 and $0.94 \mathrm{eV}$ for $\mathrm{CeO}_{2-\mathrm{x}}(110)$ and $\mathrm{Ce}_{0.75} \mathrm{Zr}_{0.25} \mathrm{O}_{2}-\mathrm{x}$ (110), respectively. Indeed, a bent $\mathrm{CO}_{2}{ }^{-}$species was found on $\mathrm{Ce}_{0.75} \mathrm{Zr}_{0.25} \mathrm{O}_{2}$ (110), as shown in Fig. 1c. It has $\mathrm{C}-\mathrm{O}$ bonds of 1.26-1.28 $\AA$ long and the $\mathrm{O}-\mathrm{C}-\mathrm{O}$ bond angle of $136.1^{\circ}$; and it possesses 16.8 valence electrons according to 
the Bader analysis. Nevertheless, as shown in Fig. $4 \mathrm{~b}$, the total energy of the $\mathrm{CO}_{2}{ }^{-} / \mathrm{Ce}_{0.75} \mathrm{Zr}_{0.25} \mathrm{O}_{2}$ (110) configuration is $71.5 \mathrm{kcal} / \mathrm{mol}$ higher than that of the ground state (i.e. the O-bridging carbonate configuration) of $\mathrm{CO} / \mathrm{Ce}_{0.75} \mathrm{Zr}_{0.25} \mathrm{O}_{2}$ (110). Moreover, the reaction $\mathrm{CO}_{\mathrm{ad}}+\mathrm{O}_{\mathrm{L}} \rightarrow \mathrm{CO}_{2}$,gas $+\mathrm{d}_{\mathrm{L}}$ on the $\mathrm{Ce}_{0.75} \mathrm{Zr}_{0.25} \mathrm{O}_{2}$ (110) surface is endothermic and the energy cost is $17.5 \mathrm{kcal} / \mathrm{mol}$ if $\mathrm{d}_{\mathrm{L}}$ is created at the $\mathrm{Ce}-\mathrm{Zr}$ bridge site. Therefore, we believe that $\mathrm{Ce}_{0.75} \mathrm{Zr}_{0.25} \mathrm{O}_{2}$ (110) is still inactive for direct $\mathrm{CO}$ oxidation, although it is somewhat better than $\mathrm{CeO}_{2}(110)$. We found that $\mathrm{CO}_{2}{ }^{-}$/ $\mathrm{Ce}_{0.75} \mathrm{Zr}_{0.25} \mathrm{O}_{2}$ (110) is spin polarized, with a net magnetic moment of $1.98 \mu_{\mathrm{B}} /$ cell. There are two pronounced peaks in the band gap, shown in Fig. 1c. The peak in the majority spin channel contains about one electron and its wave function localizes around the surface Ce cation. The peak in the minority spin channel represents the HOMO of the bent $\mathrm{CO}_{2}{ }^{-}$species, the $2 \pi^{*}$ orbital.

Note that no NEB calculation is needed for processes shown in Fig. $4 \mathrm{a}$ and $\mathrm{b}$ since (1) the formation of the ground state $\mathrm{CO}_{2}$,ad structure on $\mathrm{Ce}_{0.75} \mathrm{Zr}_{0.25} \mathrm{O}_{2}$ (111) is direct and exothermic; and (2) the bent $\mathrm{CO}_{2}$,ad structure is much higher in energy as compared with the adsorption state for $\mathrm{CO} / \mathrm{Ce}_{0.75} \mathrm{Zr}_{0.25} \mathrm{O}_{2}$ (110) so the chance to this structure is negligible.

\section{Conclusion}

In conclusion, we addressed an important issue for $\mathrm{CO}$ oxidation on redox oxides: the role of lattice oxygen, through systematic first principles studies. Unlike traditional density functional calculations, we explored metastable geometries, in particular, those with the $\mathrm{CO}_{2, \mathrm{ad}}$ groups. It is intriguing that $\mathrm{CO}$ directly forms $\mathrm{CO}_{2}$ with the lattice $\mathrm{O}$ on $\mathrm{CeO}_{2}$ (111) and $\mathrm{Ce}_{0.75} \mathrm{Zr}_{0.25} \mathrm{O}_{2}$ (111) and desorbs easily afterward from the deficient substrate. $\mathrm{Zr}$ dopant can facilitate the $\mathrm{CO}$ oxidation process. This can be attributed to several factors: (1) the smaller size of $\mathrm{Zr}^{4+}$ than $\mathrm{Ce}^{4+}$, which releases stress for the creation of $\mathrm{Ce}^{3+}$; (2) the smaller reduction energy [4, 29]; and (3) the higher oxygen mobility of the $\mathrm{Zr}$-doped ceria as compared with the pure ceria [30]. Since the binding energies of $\mathrm{CO}$ are rather high on the clean and $\mathrm{Zr}$-doped $\mathrm{CeO}_{2}$ (110), the reaction can be easily poisoned and the (110) surfaces remain inactive. We believe that the simple model here captures the main step of the Mars-van Krevelen mechanism of $\mathrm{CO}$ oxidation. Our findings satisfactorily explain experimental observations [5] and give indispensable insights for rational manipulations of composition and structure of nanocatalysts that involve oxides.

Acknowledgment This work was supported by the National Natural Science Foundation of China (grant no. 10674042) and the Innovation
Scientists and Technicians Troop Construction Projects of Henan Province, China (grant no. 104200510014). RW also acknowledges support from DOE-BES (grant no. DE-FG02-04ER15611).

Open Access This article is distributed under the terms of the Creative Commons Attribution Noncommercial License which permits any noncommercial use, distribution, and reproduction in any medium, provided the original author(s) and source are credited.

\section{References}

1. Charles TC, Charles HFP (2005) Science 309:713

2. Trovarelli A (1996) Catal Rev Sci Eng 38:439-520

3. Rodriguez JA (2005) Abstracts of papers, 229th ACS national meeting, San Diego, CA, United States, 13-17 March 2005:IEC123

4. Yang Z, Woo TK, Hermansson K (2006) J Chem Phys 124:224704

5. Masui T, Imanaka N (2003) Mater Integr 16:29-33

6. Widmann D, Leppelt R, Behm RJ (2007) J Catal 251:437-442

7. Mars P, van Krevelen DW (1954) Chem Eng Sci 3:41

8. Shapovalov V, Metiu H (2007) J Catal 245:205-214

9. Chen $\mathrm{Y}, \mathrm{Hu}$ P, Lee M-H, Wang H (2008) Surf Sci 602:1736-1741

10. Kresse G, Furthmuller J (1996) Comput Mater Sci 6:15-50

11. Perdew JP, Burke K, Ernzerhof M (1996) Phys Rev Lett 77:3865-3868

12. Kresse G, Furthmuller J (1996) Phys Rev B 54:11169

13. Bloechl PE (1994) Phys Rev B 50:17953-17979

14. Anisimov VI, Zaanen J, Andersen OK (1991) Phys Rev B 44:943-954

15. Nolan M, Parker SC, Watson GW (2005) Surf Sci 595:223-232

16. Andersson DA, Simak SI, Johansson B, Abrikosov IA, Skorodumova NV (2007) Phys Rev B 75:035109

17. Pacchioni G (2008) J Chem Phys 128:182505-182510

18. Monkhorst HJ, Pack JD (1976) Phys Rev B 13:5188

19. Henkelman G, Uberuaga BP, Jónsson H (2000) J Chem Phys 113:9901

20. Eyring L (1979) In: Gschneider KA, Eyring L (eds) Handbook on the physics and chemistry of rare earths. North-Holland, Amsterdam

21. Rodriguez JA, Hanson JC, Kim J-Y, Liu G, Iglesias-Juez A, Fernandez-Garcia M (2003) J Phys Chem B 107:3535-3543

22. Hammer B, Hansen LB, Norskov JK (1999) Phys Rev B 59:7413-7421

23. Siokou A, Nix RM (1999) J Phys Chem B 103:6984-6997

24. Yang Z, Luo G, Lu Z (2007) J Chem Phys 127:074704

25. Yang Z, Woo TK, Hermansson K (2004) Chem Phys Lett 396:384-392

26. Nolan M, Watson GW (2006) J Phys Chem 110:16600-16606

27. Henkelman G, Arnaldsson A, Jonsson H (2006) Comput Mater Sci 36:254

28. Chen H (2005) Advanced inorganic chemistry. Higher Education Press, Beijing

29. Yang Z, Wei Y, Fu Z, Lu Z, Hermansson K (2008) Surf Sci 602:1199-1206

30. Nolan M, Fearon JE, Watson GW (2006) Solid State Ion 177:3069-3074

31. Yang Z, Woo TK, Baudin M, Hermansson K (2004) J Chem Phys 120:7741-7749 